\title{
СОСТАВЫ ДЛЯ РЕМОНТА И ВОССТАНОВЛЕНИЯ КАМЕННЫХ КОНСТРУКЦИЙ ЗДАНИЙ И СООРУЖЕНИЙ
}

\section{Успанова А.C., Батаев И.И.}

\author{
ГГНТУ им. акад. М.Д. Миллионщикова, г. Грозный
}

Исследование сухих растворных смесей для ремонта и восстановления каменных конструкиий очень востребовано в связи с их сильным моральным и физическим износом. Особенно сильные напряжения испытывает растворная часть, которая в условиях сильных динамических нагрузок, деформируется и влечет за собой разрушение всей каменной конструкиии. Для ремонта и восстановления данных конструкиий предлагается использовать сухие ремонтные смеси.

Ключевые слова: сухие строительные смеси, каменные конструкции, эксплуатация, ремонт, износ, растворная смесь.

При эксплуатации зданий и сооружений в течение длительного времени различные конструкции или здание в целом может терять свои первоначальные эксплуатационные свойства. Как и любая материальная вещь или же результат антропогенной деятельности они также подвержены изнашиванию. Различают два вида износа зданий и сооружений - это моральный и физический. Под моральным износом подразумевается потеря функционального и эстетического назначения, а вот под физическим, потеря конструктивных и эксплуатационных качеств. Рассмотрим более подробно термин физический износ каменных конструкций. При физическом износе каменные конструкции подвергаются динамическому и температурному воздействию, деформациям и проявляется все это в виде трещин, сколов и расхождения кладки.

Существуют эффективные технологии и составы для восстановления и ремонта каменных конструкций, применяемые в различных регионах нашей страны. В большинстве случаев, для восстановления дефектов кладки применяют традиционный цементно-песчаный раствор, специальные ремонтные составы, сухие строительные смеси с добавками - вид применяемого материала зависит от местоположения конструкции, условий эксплуатации и возможности использования средств механизации. В последнее время наряду с затворяемыми растворными смесями все больше применяют готовые сухие строительные смеси, которые имеют широкий диапазон применения.

Ремонтные сухие смеси находят широкое применение не только для восстановления каменных конструкций, но и для устранения дефектов в бетонных и железобетонных конструкциях, для оштукатуривания поверхностей наружных и внутренних стен, отделочных и декоративных работ [1]. 
До начала работ по ремонту каменных конструкций, главным этапом является обследование данной конструкции с целью выявления остаточной несущей способности, степени морального и физического износа. При этом возможно применение двух методов осмотра конструкции - это разрушающий и неразрушающий методы. Применение того или иного метода зависит от вида проводимого исследования, расположения конструкции в общей системе здания (несущая или не самонесущая) и физического доступа к ней. Для каменных стен различают три основных вида разрушения - сильное, среднее, и слабое: слабым считают разрушение тела конструкции до пятнадцати процентов, среднее - двадцать пять, и сильное - пятьдесят процентов, рис. 1.

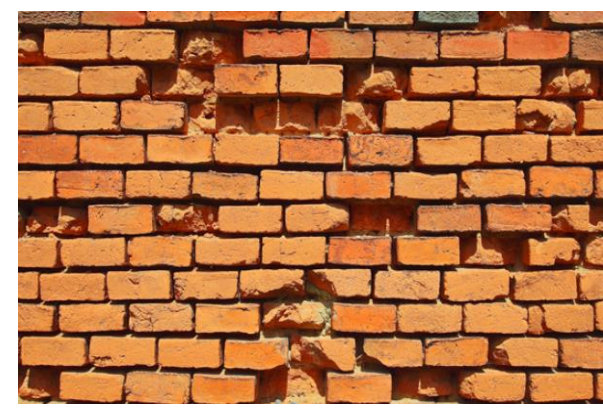

а) слабое разрушение каменной кладки

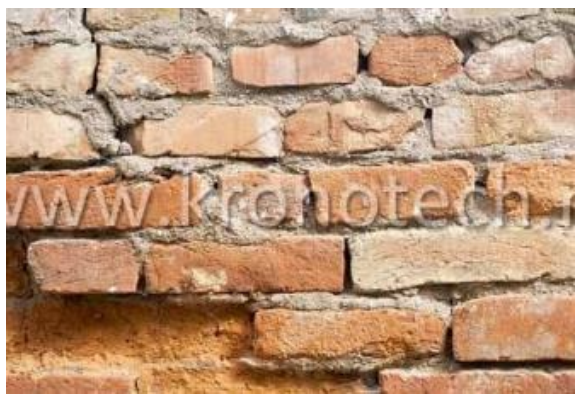

б) среднее разрушение каменной кладки

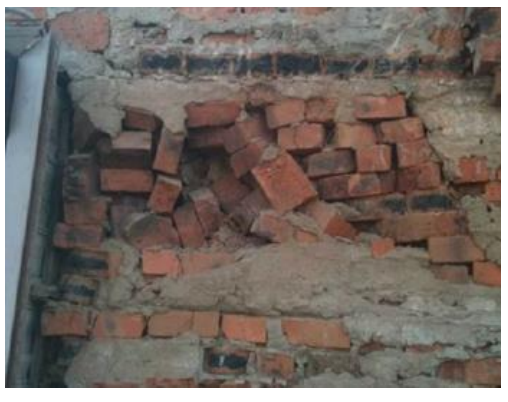

в) сильное разрушение каменной кладки

Рис.1 - Вид каменной кладки при различной степени разрушения

После проведенных обследовательских работ и испытания отобранных образцов заключается дефектный акт. На основе дефектного акта принимается заключение о проведении восстановительных работ, с указанием объемов и метода восстановления, применяемых строительных материалов, технических средств и т.П.

На сегодняшний день существует огромное количество ремонтных смесей. Для достижения большего качества, производители используют различные зарубежные добавки. Это позволяет модифицировать ремонтные смеси, повышая такие качества как прочность, адгезию, морозостойкость, водонепроницаемость, а также коррозионную стойкость [2]. Для условий Чеченской республики особенно важна адгезия, водонепроницаемость и прочность смеси, т.к. повышенная влажность провоцирует высолообразование и разрушение каменной кладки, а высокая сейсмичность требует высоких показателей адгезии и прочности от применяемой ремонтной смеси. Так, на основе анализа разрушений землетрясения 2008 года, мы видим, что наибольшее разрушение получили именно каменные конструкции с практически полным разрушением растворной части, рис. 2. 

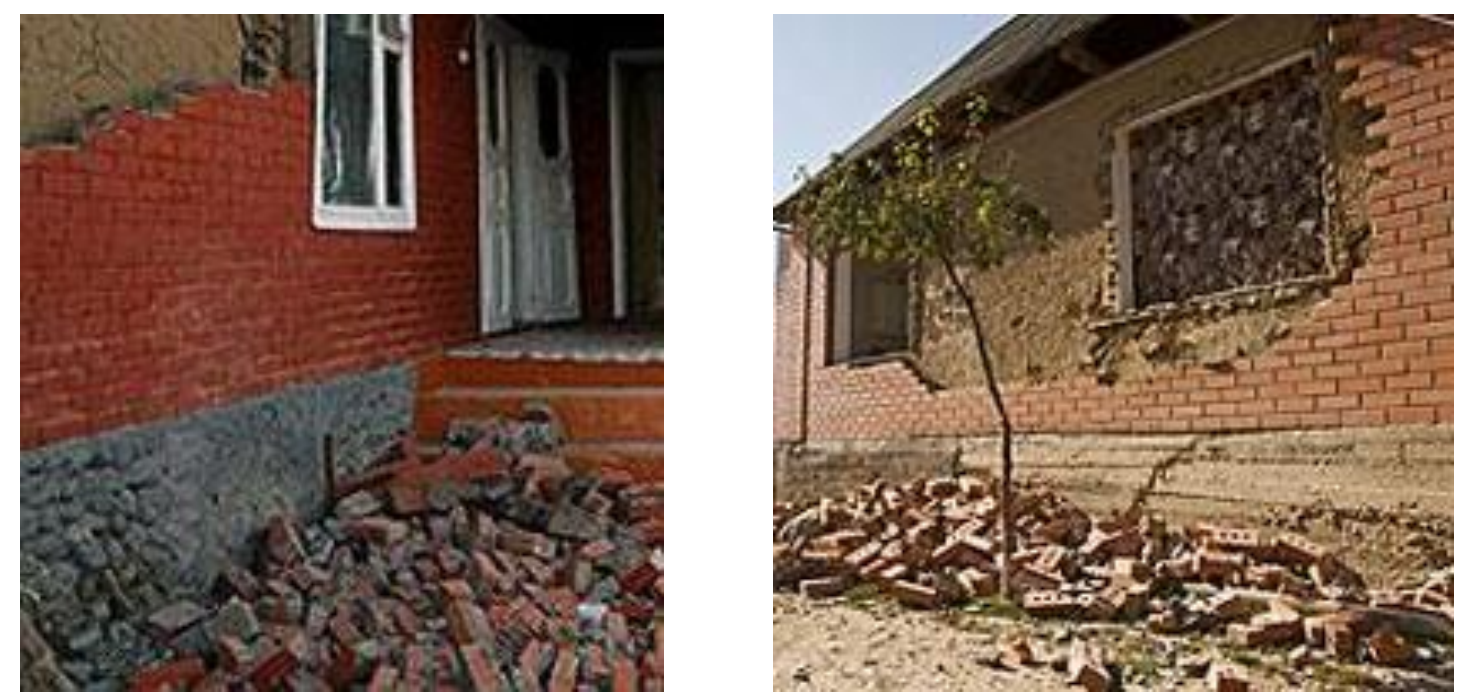

Рис. 2 - Разрушение каменной кладки при землетрясении в 2008 году в Чеченской Республике

Для каждой ремонтной смеси добавляют свой тип добавки - это зависит от вида ремонта и уникальности конструкции. Также в составе ремонтной смеси могут быть использованы техногенные заполнители и наполнители, возможно также применение нескольких комбинированных добавок для повышения качества смеси [3].

Но главным фактором достижения качества остаются такие пункты как: сырьевая база, правильная дозировка компонентов, а также смешивание. Отдельного внимания заслуживает процесс смешивания, так как многое в качестве выпускаемой продукции зависит и от этого пункта. Существуют несколько способов технологии приготовлении ремонтных составов:

a) когда все компоненты перемешиваются одновременно;

b) когда сначала перемешиваются цемент + наполнитель, затем вода с растворимыми добавками;

c) когда цемент перемешивается с добавками затем с остальными компонентами.

Каждый из этих способов имеет свои достоинства и недостатки, и их применение зависит от функционального назначения ремонтного состава. Для процесса перемешивания растворных смесей созданы и существуют множество смесительных установок, но их применение не всегда возможно из-за условий или объемов работ. Использование пакетированных ремонтных смесей практически не имеет ограничений, т.к. они могут быть транспортированы в любую точку региона и имеют небольшие объемы для затворения, что рационально при небольших объемах работ [4,5].

Для ремонта каменных конструкций предлагается использовать традиционные сухие цементные смеси, растворные смеси на известковом вяжущем, смешанном вяжущем или добавками к растворной смеси. Использование тех или иных растворов зависит от функционального назначения конструкции, необходимой прочности каменной кладки и условий эксплуатации. Цементные растворные смеси обладают повышенной 
прочностью, устойчивостью к агрессивным воздействиям внешней среды, но уступают растворным смесям на смешанных вяжущих с минеральными добавками по технологичности и жизнеспособности. Для повышения технологических свойств растворных смесей необходимы экспериментальные исследования влияния различных минеральных добавок, заполнителей техногенного или некондиционные природного происхождения на качество композитов. Все это представляет несомненный научный интерес и служит посылом новых исследований и научных публикаций.

Таким образом, сухие строительные смеси для ремонта каменных конструкций востребованы и нуждаются в более подробном изучении и разработке рациональных рецептур.

Исследование выполнено при финансовой поддержке РФФИ в рамках научного проекта № 18-48-200001.

\section{Список литературы}

1. Дворкин Л. И., Дворкин О. Л. Строительные материалы из отходов промышленности / Л. И. Дворкин. Ростов н/Д.: Феникс, 2007. 368 с.

2. Баженов Ю. М. Модифицированные высококачественные бетоны / Баженов Ю. М., Демьянова В. С., Калашников В. И. М.: АСВ, 2006. 289 с.

3. Ходаков Г. С. Тонкое измельчение строительных материалов. М.: Издательство литературы по строительству, 1972. 239. С.

4. Муртазаев С-А. Ю., Саламанова М. Ш., Бисултанов Р. Г. Высококачественные модифицированные бетоны с использованием вяжущего на основе реакционно-активного минерального компонента // Строительные материалы. 2016. № 8. С. 74-80.

5. Боженов, П.И. Комплексное использование минерального сырья и экология / П.И. Боженов. - М.: Изд-во ассоциации строительных вузов, 1994. $265 \mathrm{c}$. 